\title{
Overweight, obesity and fat distribution in 50- to 64-year-old participants in the European Prospective Investigation into Cancer and Nutrition (EPIC)
}

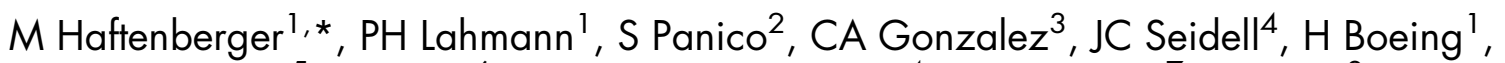 \\ MC Giurdanella ${ }^{5}$, V Krogh ${ }^{6}$, HB Bueno-de-Mesquita ${ }^{4}$, PHM Peeters ${ }^{7}, G^{2}$ Skeie $^{8}$,

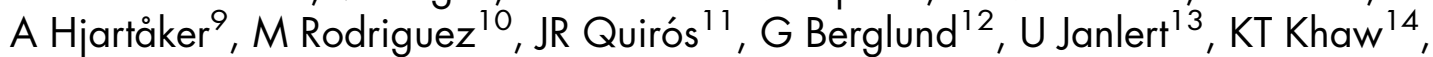 \\ EA Spencer ${ }^{15}, \mathrm{~K}$ Overvad $^{16}$, A Tiønneland ${ }^{17}, \mathrm{~F}$ Clavel-Chapelon ${ }^{18}$, B Tehard ${ }^{18}$, \\ AB Miller ${ }^{19}$, K Klipstein-Grobusch ${ }^{1}$, V Benetou ${ }^{20}, G$ Kiriazi $^{20}, E$ Riboli ${ }^{21}$ and N Slimani ${ }^{21}$ \\ 'Department of Epidemiology, German Institute of Human Nutrition, Arthur Scheunert Allee 114- 116, D-14558 \\ Potsdam-Rehbrücke, Germany: ${ }^{2}$ Department of Clinical and Experimental Medicine, Federico II University, Naples, Italy: \\ ${ }^{3}$ Department of Epidemiology, Catalan Institute of Oncology, Barcelona, Spain: ${ }^{4}$ Centre of Chronic Diseases \\ Epidemiology, National Institute of Public Health and the Environment, Bilthoven, The Netherlands: ${ }^{5}$ Cancer Registry, \\ 'Civili - M.P. Arezzo' Hospital, Ragusa, Italy: ${ }^{6}$ Epidemiology Unit, National Cancer Institute, Milan, Italy: ${ }^{7}$ Julius Center \\ for General Practice and Patient Oriented Research, University of Utrecht, The Netherlands: ${ }^{8}$ Institute for Community \\ Medicine, University of Tromsø, Norway: ${ }^{9}$ Section for Medical Statistics, University of Oslo, Norway: ${ }^{10}$ Andalusian \\ School of Public Health, Granada, Spain: ${ }^{11}$ Council for Health and Social Affairs of Asturia, Oviedo, Spain: \\ ${ }^{12}$ Department of Medicine, Lund University, Malmö University Hospital, Sweden: ${ }^{13}$ Department of Public Health and \\ Clinical Medicine, University of Umeå, Sweden: ${ }^{14}$ Department of Public Health and Primary Care, School of Clinical \\ Medicine, University of Cambridge, UK: ${ }^{15}$ Cancer Research UK, Epidemiology Unit, University of Oxford, UK: \\ ${ }^{16}$ Department of Epidemiology and Social Medicine, University of Aarhus, Denmark: ${ }^{17}$ Danish Cancer Society, \\ Copenhagen, Denmark: ${ }^{18}$ INSERM, E3N-EPIC Group, Institute Gustave Roussy, Villejuif, France: ${ }^{19}$ Division of Clinical \\ Epidemiology, German Cancer Research Centre, Heidelberg, Germany: ${ }^{20}$ Department of Hygiene and Epidemiology, \\ School of Medicine, University of Athens, Greece: ${ }^{21}$ International Agency for Cancer Research, Lyon, France
}

\begin{abstract}
Objective: To describe anthropometric characteristics of participants of the European Prospective Investigation into Cancer and Nutrition (EPIC).

Design: A cross-sectional analysis of baseline data of a European prospective cohort study.

Subjects: This analysis includes study populations from 25 centres in nine European countries. The British populations comprised both a population-based and a healthconscious' group. The analysis was restricted to 83178 men and 163851 women aged 50-64 years, this group being represented in all centres.

Methods: Anthropometric examinations were undertaken by trained observers using standardised methods and included measurements of weight, height, and waist and hip circumferences. In the 'health-conscious' group (UK), anthropometric measures were predicted from self-reports.

Results: Except in the 'health-conscious' group (UK) and in the French centres, mean body mass index (BMI) exceeded $25.0 \mathrm{~kg} \mathrm{~m}^{-2}$. The prevalence of obesity $\left(\mathrm{BMI} \geq 30 \mathrm{~kg} \mathrm{~m}^{-2}\right.$ ) varied from $8 \%$ to $40 \%$ in men, and from $5 \%$ to $53 \%$ in women, with high prevalences $(>25 \%)$ in the centres from Spain, Greece, Ragusa and Naples (Italy) and the lowest prevalences $(<10 \%)$ in the French centres and the healthconscious' group (UK). The prevalence of a large waist circumference or a high waistto-hip ratio was high in centres from Spain, Greece, Ragusa and Naples (Italy) and among women from centres in Germany and Bilthoven (The Netherlands).

Conclusions: Anthropometric measures varied considerably within the EPIC population. These data provide a strong base for further investigation of anthropometric measures in relation to the risk of chronic diseases, especially cancer.
\end{abstract}

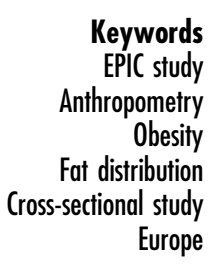

Anthropometric measures such as weight, height, and waist and hip circumferences have been shown to be related to risk of many chronic diseases ${ }^{1,2}$. The relationship between body mass index (BMI) and risk of chronic disease is well established for diabetes mellitus ${ }^{1-4}$, several cancer types ${ }^{5-17}$, coronary heart disease and hypertension ${ }^{1,3,18}$ and, in some populations, for total mortality $^{3,19}$. In particular, a high waist-to-hip ratio (WHR) 
is associated with elevated total mortality ${ }^{20,21}$ and risk for diabetes mellitus ${ }^{22}$, coronary heart disease $\mathrm{e}^{18,21,23}$ and hypertension $^{22}$.

There is considerable evidence for associations between obesity and increased risk of postmenopausal breast cancer $^{10-12,15}$, colon cancer ${ }^{7,8,13,15}$, endometrial cancer ${ }^{9,15}$ and renal cell cancer ${ }^{15,16}$. Obesity is possibly also associated with increased risk of prostate cancer ${ }^{5,6,15}$, adenocarcinoma of the oesophagus ${ }^{15,17}$ and thyroid cancer $^{15}$. WHR and waist circumference (WC), as indicators of central adiposity, contribute to breast cancer risk independently of $\mathrm{BMI}^{14}$

Further evidence on the role of anthropometric factors in the risk of cancer and other diseases is needed. These studies should preferably be performed in large populations with a high variability of disease risk and a large range of anthropometric values, and should make use of several anthropometric measures. The European Prospective Investigation into Cancer and Nutrition (EPIC) has the potential for comparison of data from large numbers of subjects with high variability in both disease risk and anthropometric characteristics. The EPIC project is a multicentre prospective cohort study designed to investigate the relation between diet, nutritional and metabolic characteristics, various lifestyle factors and disease risk, particularly cancer. EPIC includes 23 administrative centres in 10 countries with individual national cohorts comprising 28000-88000 subjects. Over 500000 subjects participated in the baseline examination of the EPIC study. The EPIC study was set up by study groups from France, Germany, Greece, Italy, Spain, The Netherlands and the UK; it was subsequently joined by already existing cohorts from Sweden, Denmark and Norway with a similar set of procedures and study variables. Anthropometric measurements at the baseline examination of the EPIC study included weight and height measurements as well as measurements of waist and hip circumferences ${ }^{24}$.

The present paper describes baseline data regarding the distribution of weight, height, and waist and hip circumferences over the different EPIC study populations and explores the variability of these anthropometric characteristics between the EPIC study populations. The description is restricted to the age range 50-64 years, which is represented in all EPIC centres.

\section{Methods}

\section{Subjects}

This study presents baseline data from the EPIC study, which were collected between 1992 and 2000. The selection of study populations in each study centre was largely influenced by practical considerations of obtaining adequate participation and ensuring long-term follow-up, and, as such, study populations were not intended to be representative of entire regions. The study populations were either population-based (Bilthoven, The Netherlands, describing population-based samples from the towns of Amsterdam, Doetinchem and Maastricht; Greece; Germany; Sweden; Denmark; Norway; part of the study population from the UK, Spain and Italy) or included special groups such as participants in breast cancer screening (Utrecht, The Netherlands; Florence, Italy), blood donors (part of the study populations from Spain and Italy), teachers and school workers (France) or vegetarians, vegans and other health-conscious individuals (part of the study population from the UK). In France, Norway, Utrecht (The Netherlands) and Naples (Italy), only women were examined. The age range differed substantially between centres. To reduce the heterogeneity between centres due to these age differences, the present analysis was restricted to the age group 50-64 years, which was represented in all centres. A total of 84515 men and 166065 women were 50-64 years old. Anthropometric data were available for 83178 men and 163851 women in this age group. Study populations, sample sizes and sources of populations are described in more detail elsewhere ${ }^{25}$. At the time of the analysis, no anthropometric data were available for Norway.

\section{Antbropometric measurements}

Details of the anthropometry core protocols in each EPIC centre are described in Table 1. In Umeå (Sweden), anthropometric data collection was restricted to measurement of weight and height. In the 'health-conscious' group (UK), in addition to self-reports of weight, height and circumferences of waist and hip for all participants, measurements of weight, height and circumferences were available in a sub-group. In the French centres, weight and height were requested by questionnaire, and subsequently weight, height and waist and hip circumferences were measured in a sub-group. In each centre, hip circumference (HC) was measured either at the widest point or over the buttocks. These two measurement methods used to assess $\mathrm{HC}$ are generally in agreement ${ }^{26}$. WC was measured either at the narrowest torso circumference (France; Italy; Spain; UK; Utrecht, The Netherlands; Heidelberg, Germany; Greece; Denmark) or midway between the lower ribs and the iliac crest (Spain; Bilthoven, The Netherlands; Greece; Germany; Malmö, Sweden). In Spain, Greece and Heidelberg (Germany), a combination of methods was used, whereby the majority of participants were measured at the narrowest circumference. If the narrowest circumference could not be identified, WC was measured midway between the lower ribs and the iliac crest.

Overall, the proportion of missing values for anthropometric measures was less than 5\%. However, in the British cohort representing the general population, anthropometric measurements were missing in $12 \%$ of all participants. In $18 \%$ of the men from Florence (Italy) and in $13 \%$ of the British men representing the 'health- 


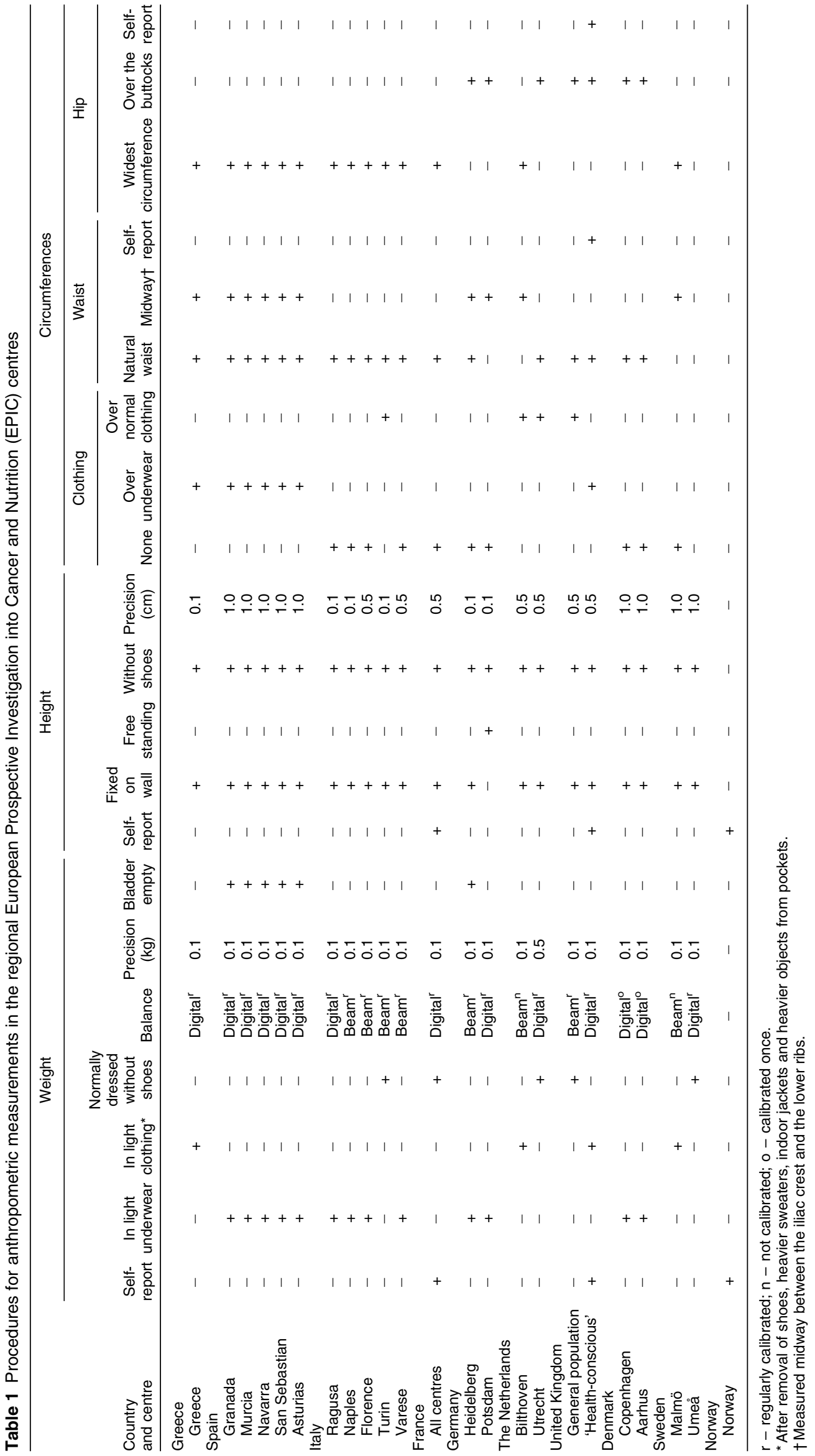


conscious' group, data on waist and hip circumferences were missing.

The anthropometric data were adjusted to reduce heterogeneity due to protocol differences in clothing worn during measurement. In most Italian centres, as well as in Spain, Germany and Denmark, weight was measured on subjects in light underwear. In the centres of France, Turin (Italy), the general population of the UK, Umeå (Sweden) and Utrecht (The Netherlands), subjects wore normal clothing without shoes, while in the remaining centres (the 'health-conscious' group (UK); Bilthoven, The Netherlands; Greece; Malmö, Sweden) weighing was undertaken with subjects in light clothing after the removal of shoes, heavier sweaters or indoor jackets and emptying heavy objects from pockets. For subjects who were normally dressed and without shoes, correction factors of $-1.5 \mathrm{~kg}$ for weight and $-2.0 \mathrm{~cm}$ for circumferences were adopted from an earlier multi-centre study ${ }^{27}$. In centres where weight was measured with subjects in light clothing only (the 'health-conscious' group (UK); Bilthoven, The Netherlands; Greece; Malmö, Sweden), the adjustment for weight was $-1.0 \mathrm{~kg}$.

In 965 men (33\% of all men) and 1464 women (16\% of all women) aged 50-64 years old from the 'healthconscious' group (UK), self-reported and measured anthropometric measures were determined within 3 weeks. These data showed discrepancies between measurements and self-reports. Self-reported weight, waist and hip circumferences were underestimated and self-reported height was overestimated. The degree of the over- or underestimation was dependent on the level of the anthropometric measure and age: a higher level of underestimation of weight was observed in heavier subjects. Overestimation of height was more common among shorter subjects. Waist and hip circumferences were underestimated to greater extents by heavier subjects. The accuracy of anthropometric measures in subjects with only self-reports was improved by using prediction equations (shown in the Appendix). Sexspecific predictions were derived from subjects with both measured and self-reported measures by linear regression models, with the measured parameter as the dependent variable and the self-reported variable and age as the independent variables.

In the French centres, weight and height were measured in $31 \%$ of all women, while self-reports were available for all women. For the French women with both self-reported and measured data, the time interval between self-reports and measurements varied between less than 1 month and 6 years. The maximum time interval between measurements and self-reports, considered necessary to allow for a reasonable comparison of self-reported and measured values, was 3 months. Due to the insufficient number of eligible women within this time interval $(n=115)$, prediction equations from self-reports were not determined. Instead, we present the self-reported and the measured values for the French women. In statistical questions and data comparison, the measured values were used. A study of the validity of self-measured anthropometric measures among 152 French women showed reasonable agreement between self-measured weight and height and those measured directly by a technician (B. Tehard, personal communication).

BMI was calculated as weight $(\mathrm{kg})$ divided by height $(\mathrm{m})$ squared. Subjects were classified into different BMI categories according to the World Health Organization guidelines as follows: subjects with a BMI below $18.5 \mathrm{~kg} \mathrm{~m}^{-2}$ were considered underweight, subjects with a BMI between 18.5 and $24.9 \mathrm{~kg} \mathrm{~m}^{-2}$ had normal weight, subjects with a BMI between 25.0 and $29.9 \mathrm{~kg} \mathrm{~m}^{-2}$ were considered overweight and subjects with a BMI of $30.0 \mathrm{~kg} \mathrm{~m}^{-2}$ or higher were classified as obese ${ }^{1}$.

WHR was calculated as waist circumference $(\mathrm{cm})$ divided by hip circumference $(\mathrm{cm})$. Both WC and WHR are used as indicators of central obesity. Cut-off points used to identify subjects with a large WC were $102 \mathrm{~cm}$ in males and $88 \mathrm{~cm}$ in females. These values have been used previously to identify subjects with increased relative risk for the development of obesity-related risk factors ${ }^{1}$. Cutoff points to categorise subjects with a high WHR were 0.95 in men and 0.80 in women ${ }^{28}$.

\section{Statistical analysis}

Statistical analyses were carried out using the SAS statistical package, version 8.0. The centres or geographical regions were redefined, as described elsewhere ${ }^{29}$, resulting in a total of 27 analytical centres. The redefined centres include both centres and geographical regions. In the present analysis, both centres and geographical regions are described in terms of centres. At the time of the analysis, no data were available for the two centres from Norway. Therefore, results from 25 EPIC centres are described in this paper. All data analyses were stratified by gender. The arithmetic mean, standard error, and 10th, 50th (median) and 90th percentiles for weight, height, BMI, WC, HC and WHR are presented for each centre. The percentiles were used to describe the distribution of each body measure by centre. Both mean and median (50th percentile) are statistical parameters describing the central tendency of the data. We examined the shape of the distributions and the extent of skewness of the body measures. In addition, the prevalences of overweight, obesity and abdominal body fat accumulation were determined, by applying commonly used cut-off points indicating a high level of adiposity.

Due to the association between anthropometric measures and age $\mathrm{e}^{30}$, all statistical measures were adjusted for age, using the residuals of linear regression with age as the independent variable and the anthropometric measure as the dependent variable. Since differences between crude and adjusted values were small $(<1 \%)$, only the age-adjusted values are presented here. 
To describe the association between BMI and WC or WHR as indicators of fat distribution, Pearson correlation coefficients were calculated both on an individual level for each centre and on the level of the centres. In addition, the association between prevalence of obesity and prevalence of a large WC or a high WHR is described.

\section{Results}

The age-adjusted mean, standard error, and 10th, 50th and 90th percentiles of weight, height and BMI are presented in Tables 2 and 3 for men and women, respectively. The difference between mean and median was consistently less than $\pm 3.5 \%$ for each centre, indicating that the distribution of the data was symmetrical. Examination of the skewness of the sex-stratified distributions using pooled data of all centres indicated the following values for skewness: weight, 0.73 ; height, -0.12 ; and BMI, 0.89 in men; and weight, 0.98; height, - 0.07; and BMI, 1.09 in women. Mean weight varied from $77.0 \mathrm{~kg}$ (Turin, Italy) to $83.6 \mathrm{~kg}$ (Heidelberg, Germany) in men and from $60.2 \mathrm{~kg}$ (South of France) to $73.3 \mathrm{~kg}$ (Granada, Spain) in women. Mean height varied between $166.6 \mathrm{~cm}$ (Murcia, Spain) and $176.8 \mathrm{~cm}$ (Malmö, Sweden; Copenhagen, Denmark) in men and between $154.4 \mathrm{~cm}$ (Granada, Spain) and $164.5 \mathrm{~cm}$ (Utrecht, The Netherlands) in women. Mean BMI ranged from $25.2 \mathrm{~kg} \mathrm{~m}^{-2}$ (the 'health-conscious' group, UK) to
$29.3 \mathrm{~kg} \mathrm{~m}^{-2}$ (Granada and Navarra, Spain) in men and from $23.5 \mathrm{~kg} \mathrm{~m}^{-2}$ (South and South coast of France) to $30.8 \mathrm{~kg} \mathrm{~m}^{-2}$ (Granada, Spain) in women. Mean BMI exceeded $27.5 \mathrm{~kg} \mathrm{~m}^{-2}$ in the Greek and Spanish centres and in the centres of Ragusa and Naples (Italy). In the women from the French centres and the 'health-conscious' group (UK), mean BMI was less than $25.0 \mathrm{~kg} \mathrm{~m}^{-2}$.

Prevalence of underweight was less than $1 \%$ in men and $4 \%$ or less in women. In the total EPIC cohort of $50-$ to 64-year-olds with measured anthropometric data $(n=$ 245153 ), 32\% of men and $49 \%$ of women had normal weight. Large variations were observed in the distribution of normal weight, overweight and obesity across EPIC centres. Over 50\% of women from centres in France, Turin (Italy), Utrecht (The Netherlands), Malmö (Sweden) and Denmark, and men and women from the 'healthconscious' group (UK), had normal weight. Prevalence of obesity was $25 \%$ or more in the Spanish and Greek centres, as well as in the Italian centres of Ragusa and Naples (Table 4).

Overweight and obesity were observed less frequently when using self-reports of weight and height in the total cohort of French women, compared with measured data in the sub-group. In each French centre, the mean of the individual differences of BMI between self-reported and measured data was significantly negative (data not shown). Table 3 shows that the self-reported weight of all French

Table 2 Age-adjusted mean, standard error (SE), and 10th, 50th and 90th percentiles $\left(\mathrm{P}_{10}, \mathrm{P}_{50}\right.$ and $\left.\mathrm{P}_{90}\right)$ of weight $(\mathrm{kg})$, height $(\mathrm{cm})$ and body mass index (BMl; $\mathrm{kg} \mathrm{m}^{-2}$ ) in men aged 50-64 years in the European Prospective Investigation into Cancer and Nutrition (EPIC) centres

\begin{tabular}{|c|c|c|c|c|c|c|c|c|c|c|c|c|c|c|c|c|c|c|}
\hline \multirow[b]{2}{*}{ Country and centre } & \multicolumn{6}{|c|}{ Weight $(\mathrm{kg})$} & \multicolumn{6}{|c|}{ Height $(\mathrm{cm})$} & \multicolumn{6}{|c|}{$\mathrm{BMI}\left(\mathrm{kg} \mathrm{m}^{-2}\right)$} \\
\hline & $n$ & Mean & SE & $\mathrm{P}_{10}$ & $P_{50}$ & $\mathrm{P}_{90}$ & $n$ & Mean & SE & $P_{10}$ & $P_{50}$ & $P_{90}$ & $n$ & Mean & SE & $P_{10}$ & $P_{50}$ & $P_{90}$ \\
\hline \multicolumn{19}{|l|}{ Greece } \\
\hline Greece & 3664 & 80.4 & 0.2 & 65.6 & 79.6 & 95.7 & 3669 & 168.5 & 0.1 & 160.9 & 168.3 & 176.6 & 3662 & 28.3 & 0.1 & 23.7 & 28.0 & 33.2 \\
\hline \multicolumn{19}{|l|}{ Spain } \\
\hline Granada & 880 & 81.6 & 0.4 & 67.8 & 80.8 & 96.9 & 888 & 166.9 & 0.2 & 159.0 & 167.0 & 174.8 & 879 & 29.3 & 0.1 & 24.8 & 29.2 & 34.1 \\
\hline Murcia & 1265 & 79.8 & 0.3 & 66.9 & 79.1 & 93.4 & 1285 & 166.6 & 0.2 & 159.0 & 166.4 & 174.6 & 1264 & 28.7 & 0.1 & 24.7 & 28.4 & 33.0 \\
\hline Navarra & 1908 & 82.5 & 0.2 & 70.6 & 81.6 & 95.9 & 1915 & 167.8 & 0.1 & 160.6 & 168.0 & 175.3 & 1907 & 29.3 & 0.1 & 25.4 & 29.0 & 33.5 \\
\hline San Sebastian & 2144 & 81.0 & 0.2 & 68.6 & 80.1 & 94.8 & 2145 & 169.2 & 0.1 & 161.5 & 169.0 & 177.5 & 2143 & 28.3 & 0.1 & 24.7 & 28.0 & 32.4 \\
\hline Asturias & 1355 & 80.6 & 0.3 & 67.5 & 79.9 & 94.3 & 1354 & 167.7 & 0.2 & 160.1 & 167.6 & 175.2 & 1352 & 28.7 & 0.1 & 24.6 & 28.3 & 33.0 \\
\hline \multicolumn{19}{|c|}{ 30 } \\
\hline Ragusa & 1057 & 78.5 & 0.3 & 65.3 & 77.4 & 93.3 & 1057 & 167.4 & 0.2 & 159.5 & 167.4 & 175.6 & 1057 & 28.0 & 0.1 & 23.7 & 27.8 & 32.5 \\
\hline Florence & 1711 & 78.9 & 0.3 & 65.3 & 77.9 & 93.0 & 1708 & 172.1 & 0.2 & 164.1 & 172.1 & 180.0 & 1708 & 26.6 & 0.1 & 22.7 & 26.3 & 30.8 \\
\hline Turin & 2844 & 77.0 & 0.2 & 64.1 & 76.2 & 90.6 & 2846 & 171.2 & 0.2 & 162.9 & 171.0 & 179.8 & 2841 & 26.3 & 0.1 & 22.4 & 26.0 & 30.4 \\
\hline Varese & 1587 & 77.7 & 0.3 & 65.1 & 76.6 & 91.6 & 1588 & 170.7 & 0.2 & 162.9 & 170.5 & 178.8 & 1587 & 26.7 & 0.1 & 22.9 & 26.3 & 30.9 \\
\hline \multicolumn{19}{|l|}{ Germany } \\
\hline Heidelberg & 7110 & 83.6 & 0.1 & 69.6 & 82.5 & 98.9 & 7184 & 175.0 & 0.1 & 167.0 & 175.0 & 183.2 & 7100 & 27.3 & 0.0 & 23.2 & 26.9 & 31.9 \\
\hline Potsdam & 6115 & 82.6 & 0.2 & 68.6 & 81.6 & 97.8 & 6098 & 174.1 & 0.1 & 165.9 & 174.0 & 182.4 & 6086 & 27.2 & 0.0 & 23.2 & 26.9 & 31.8 \\
\hline \multicolumn{19}{|l|}{ The Netherlands } \\
\hline Bilthove & 3232 & 81.9 & 0.2 & 67.8 & 80.8 & 96.9 & 3232 & 175.1 & 0.1 & 166.2 & 175.1 & 183.6 & 3232 & 26.7 & 0.1 & 22.6 & 26.4 & 31.0 \\
\hline \multicolumn{19}{|l|}{ United Kingdom } \\
\hline General population & 6477 & 80.0 & 0.1 & 66.3 & 78.9 & 95.0 & 6475 & 174.9 & 0.1 & 166.6 & 175.1 & 183.3 & 6473 & 26.1 & 0.0 & 22.3 & 25.7 & 30.3 \\
\hline 'Health-con' & 2423 & 77.9 & 0.2 & 64.7 & 76.8 & 92.4 & 2444 & 175.6 & 0.1 & 168.1 & 176.0 & 183.2 & 2415 & 25.2 & 0.1 & 21.5 & 24.9 & 29.3 \\
\hline \multicolumn{19}{|l|}{ Denmark } \\
\hline Copenhagen & 18511 & 83.1 & 0.1 & 68.6 & 81.8 & 99.2 & 18511 & 176.8 & 0.0 & 168.7 & 176.7 & 185.1 & 18511 & 26.6 & 0.0 & 22.4 & 26.1 & 31.2 \\
\hline Aarhus & 8320 & 82.8 & 0.1 & 68.8 & 81.7 & 98.3 & 8320 & 176.3 & 0.1 & 168.4 & 176.1 & 184.4 & 8320 & 26.6 & 0.0 & 22.6 & 26.2 & 31.0 \\
\hline \multicolumn{19}{|l|}{ Sweden } \\
\hline Malmö & 7299 & 81.1 & 0.1 & 66.8 & 80.0 & 96.9 & 7299 & 176.8 & 0.1 & 168.4 & 176.8 & 185.2 & 7299 & 25.9 & 0.0 & 21.8 & 25.7 & 30.4 \\
\hline Umeå & 5155 & 80.2 & 0.2 & 66.8 & 78.8 & 94.8 & 5160 & 176.2 & 0.1 & 168.6 & 175.8 & 184.5 & 5154 & 25.8 & 0.0 & 21.9 & 25.5 & 29.8 \\
\hline
\end{tabular}

${ }^{*}$ Weight and height predicted from self-reports. 


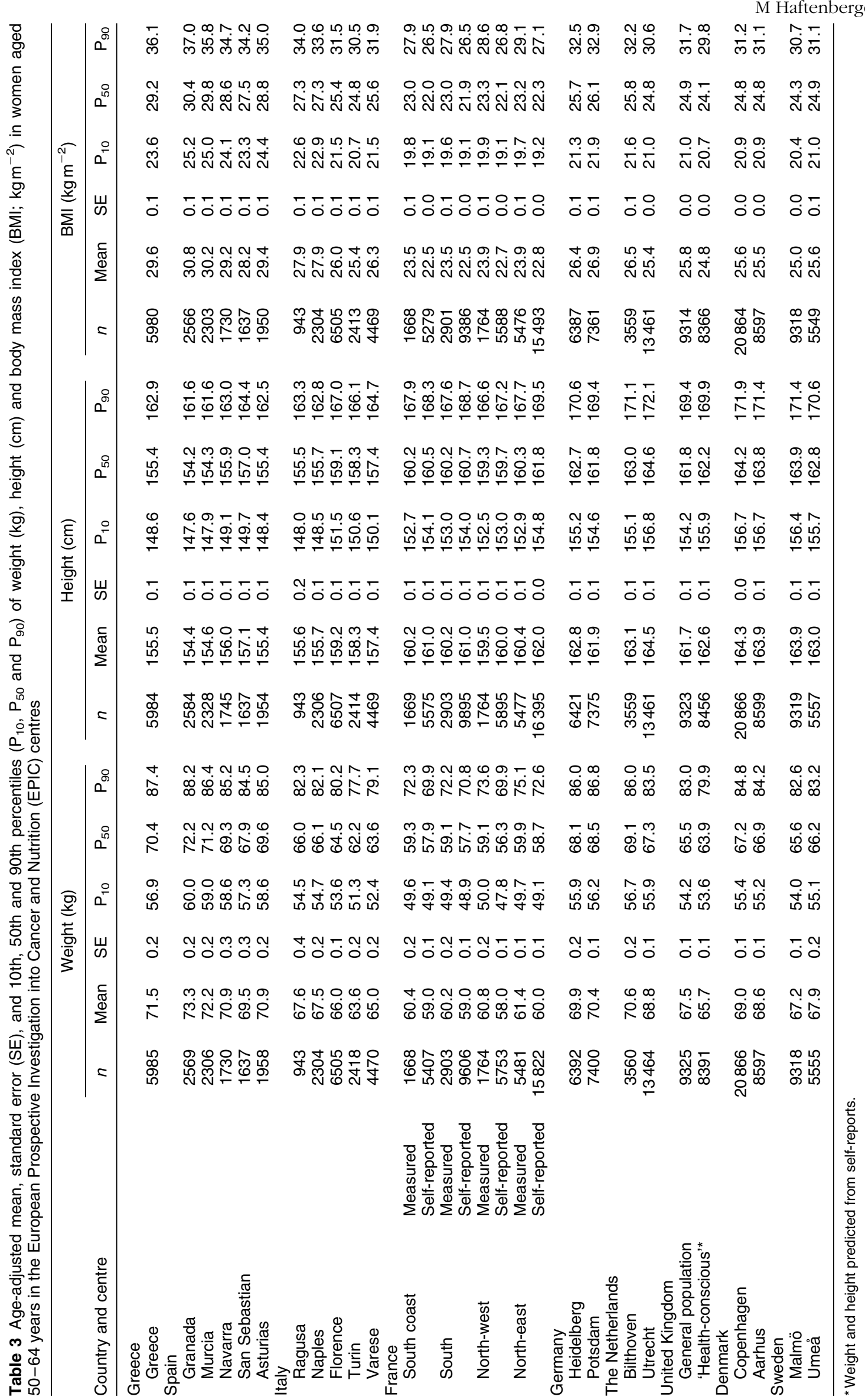




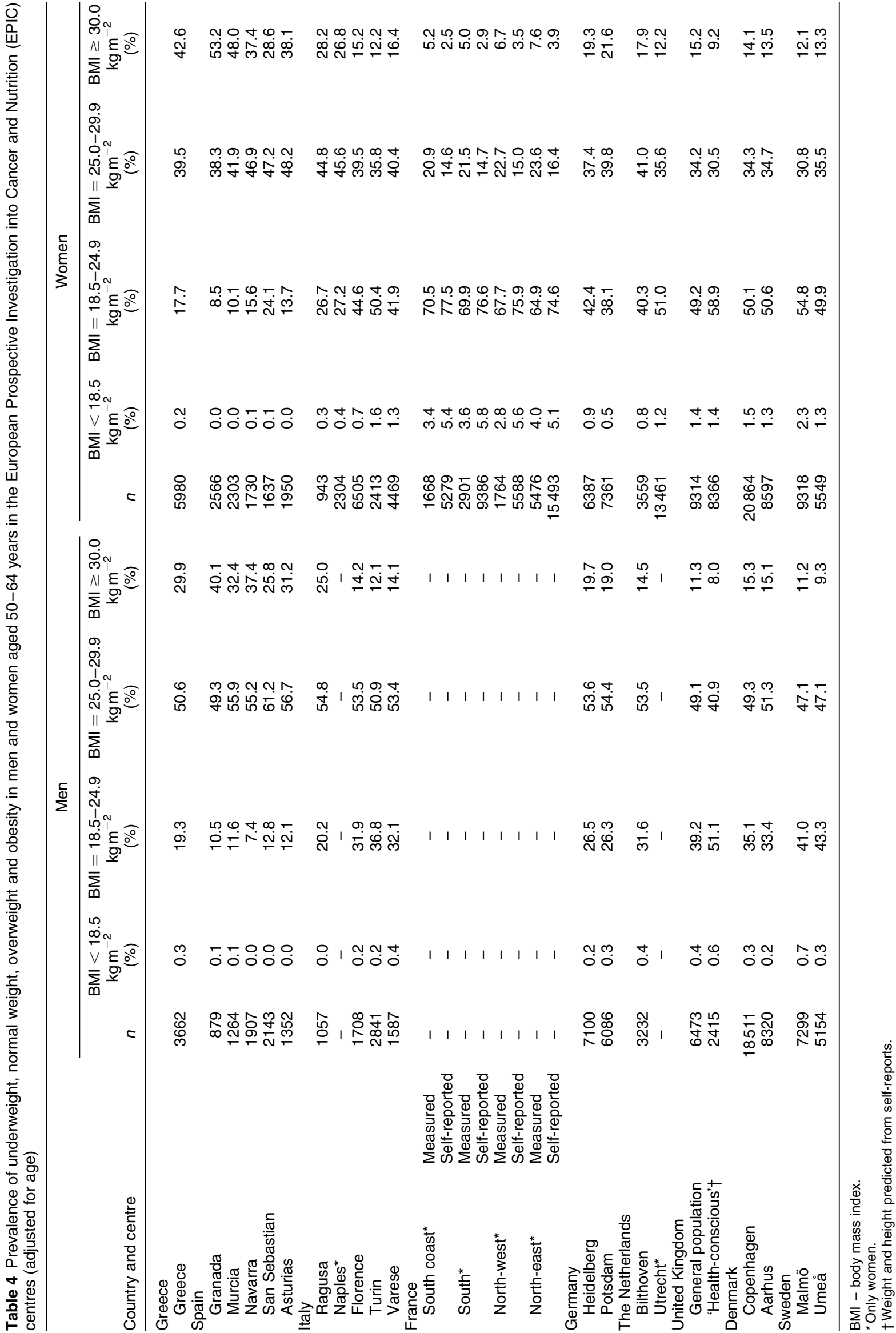


women at baseline was lower than measured weight of the sub-group. For height the opposite pattern was observed.

Descriptive statistics of waist and hip circumferences and WHR are shown in Tables 5 and 6 for men and women, respectively. The difference between mean and median was consistently less than $\pm 2.3 \%$ for each centre, indicating that the distribution of the data was symmetrical. Examination of the skewness of the sex-stratified distributions using pooled data from all centres indicated the following values for skewness: WC, 0.51; HC, 0.73; and WHR, 0.39 in men; and WC, 0.81; HC, 0.85; and WHR, 1.07 in women. WC and WHR were generally lower in women than in men, while HC in women was similar to or higher than in men in all centres. The widest range of means of WC in the different centres was observed in those centres where WC was measured at the narrowest circumference. Irrespective of the method used for measuring WC, mean WC varied from $92.1 \mathrm{~cm}$ ('health-conscious' group, UK) to $103.0 \mathrm{~cm}$ (Navarra, Spain) in men and from $77.2 \mathrm{~cm}$ (South of France) to $95.0 \mathrm{~cm}$ (Murcia, Spain) in women. Relatively high values for WC were observed in centres in Spain and Greece and in the Italian centres of Ragusa and Naples, compared with the other centres. HC ranged from $99.0 \mathrm{~cm}$ (Florence, Italy) to $106.3 \mathrm{~cm}$ (Murcia, Spain) in men and from $97.9 \mathrm{~cm}$ (South of France) to $110.7 \mathrm{~cm}$ (Murcia, Spain) in women. In men, mean WHR ranged from 0.91 ('healthconscious' group, UK) to 0.98 (Ragusa, Italy) in the centres with measurements at the narrowest circumference; from 0.94 (Asturias, Spain) to 0.97 (Granada, Murcia and Navarra, Spain) in the centres using both methods of waist measurement; and from 0.94 (Malmö, Sweden) to 0.95 (Potsdam, Germany) in the centres with measurements midway between the lower ribs and the iliac crest. In women, these ranges were 0.77 ('health-conscious' group, UK) to 0.84 (Ragusa and Naples, Italy) for the centres with measurements at the narrowest circumference; 0.82 (Heidelberg, Germany) to 0.86 (Murcia and Navarra, Spain) in the centres using both methods of waist measurement; and 0.79 (Malmö, Sweden) to 0.83 (Bilthoven, The Netherlands) in the centres with measurements of WC midway between the lower ribs and the iliac crest.

A total of $25 \%$ of men and $27 \%$ of women had a large WC, and $49 \%$ of men and $48 \%$ of women had a high WHR. There was considerable variation in the prevalence of large WC or high WHR among regional EPIC cohorts. Generally, more subjects had a high WHR than a large WC. The proportion of subjects with a large WC or a high WHR was lowest in the 'health-conscious' group (UK) and women from the French centres. A large WC and a high WHR was most often observed in men and women from the Spanish and Greek centres, as well as in women from Bilthoven (The Netherlands), Potsdam and Heidelberg (Germany), Ragusa and Naples (Italy) (Table 7).

In both men and women, BMI was highly correlated with WC and WHR, respectively, on an individual level in all centres. The correlation coefficients were on average higher between BMI and WC than between BMI and WHR, or between WC and WHR. The correlation coefficients between BMI and WC ranged from 0.71 ('healthconscious' group, UK) to 0.89 (Potsdam, Germany) in men and from 0.73 ('health-conscious' group, UK) to 0.88 (Varese and Ragusa, Italy; Potsdam, Germany) in women. The correlation coefficients between BMI and WHR ranged from 0.34 (San Sebastian, Spain) to 0.62 (Malmö, Sweden) in men and from 0.20 (Granada, Spain) to 0.50 (Aarhus, Denmark) in women. The correlation coefficients between WC and WHR ranged from 0.61 (Murcia, Spain) to 0.81 (general population and 'health-conscious' group, UK; Bilthoven, The Netherlands) in men and from 0.58 (Murcia, Spain) to 0.78 (Aarhus, Denmark) in women.

Figures 1 and 2 show the relationships between the prevalence of general obesity and the prevalence of a large WC or high WHR. Both the prevalence of a large WC and the prevalence of a high WHR were positively associated with the prevalence of general obesity. The association between the prevalence of a large WC and general obesity was stronger than that seen between the prevalence of a high WHR and general obesity. The prevalence of a large WC or a high WHR varied considerably between centres with equal prevalence of general obesity.

\section{Discussion}

This study describes the variation of anthropometric characteristics among the EPIC study populations. The sex- and centre-specific data of weight, height and BMI showed considerable variation in these measures among regional study populations and even within countries. This was particularly evident for the centres from Italy and Spain, where differences in mean BMI and prevalence of obesity were observed. Relatively high values were observed in men from the Spanish centres of Granada (southern Spain) and Navarra (north-east of Spain) and in women from the southern Spanish centres of Murcia and Granada, and in men and women from the centres of Naples and Ragusa (southern Italy), in comparison with other centres in these countries.

A direct comparison of results from EPIC with those from other studies should be interpreted with caution, as EPIC was not intended to represent the general population of the study regions. Some of the study populations from Spain and southern Italy represented special groups. Blood donors dominated the study populations from Spain and Ragusa (Italy). Interestingly, similar geographical variations in the distribution of obesity, as were shown in EPIC, have been documented in Spain and Italy in previous studies ${ }^{31-33}$. Also, in women from the Dutch centres, there was a difference in the prevalence of obesity of almost $6 \%$ between participants from the Bilthoven centre, a population-based cohort, and participants from the Utrecht centre, a cohort recruited from women 


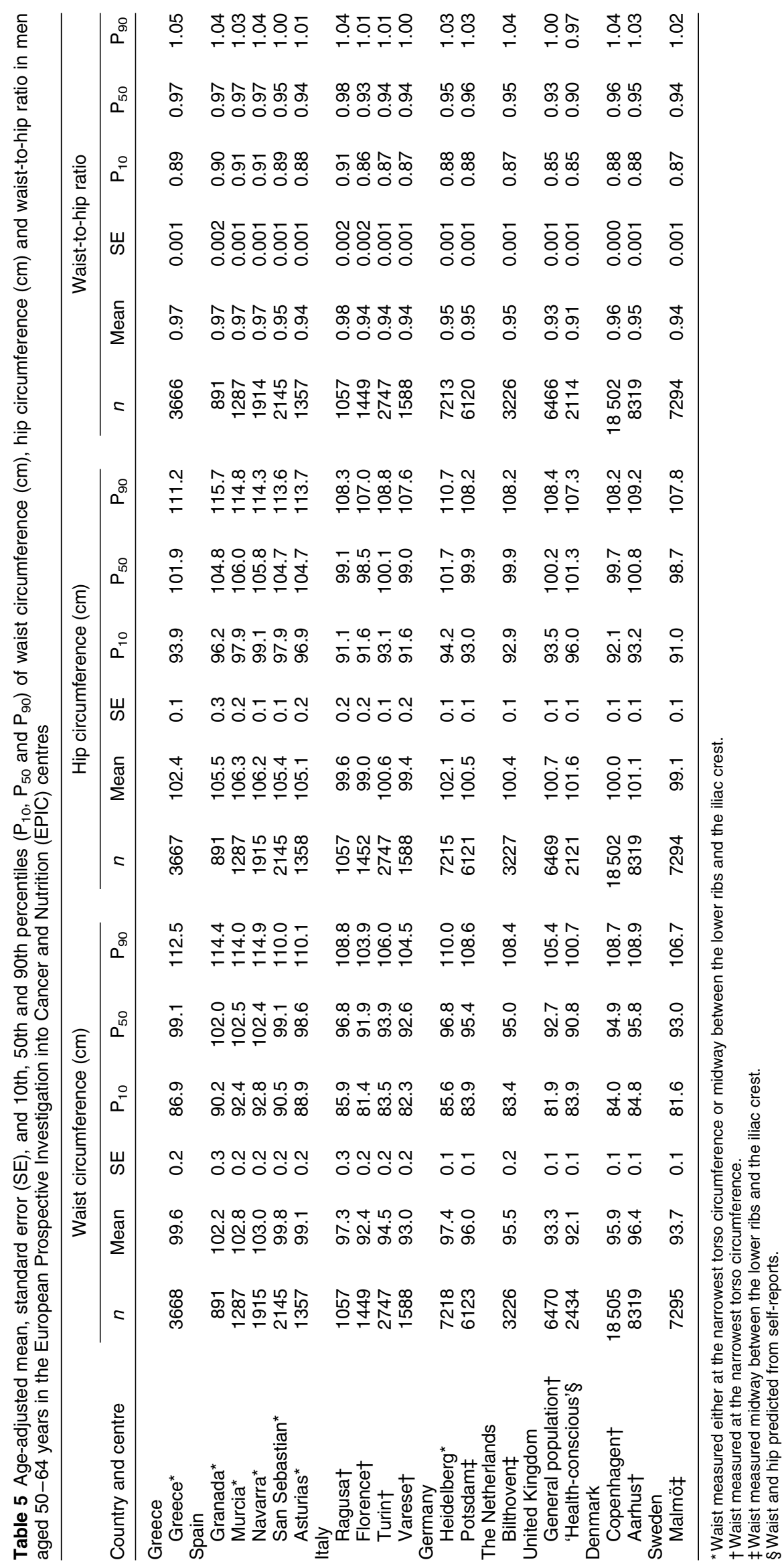




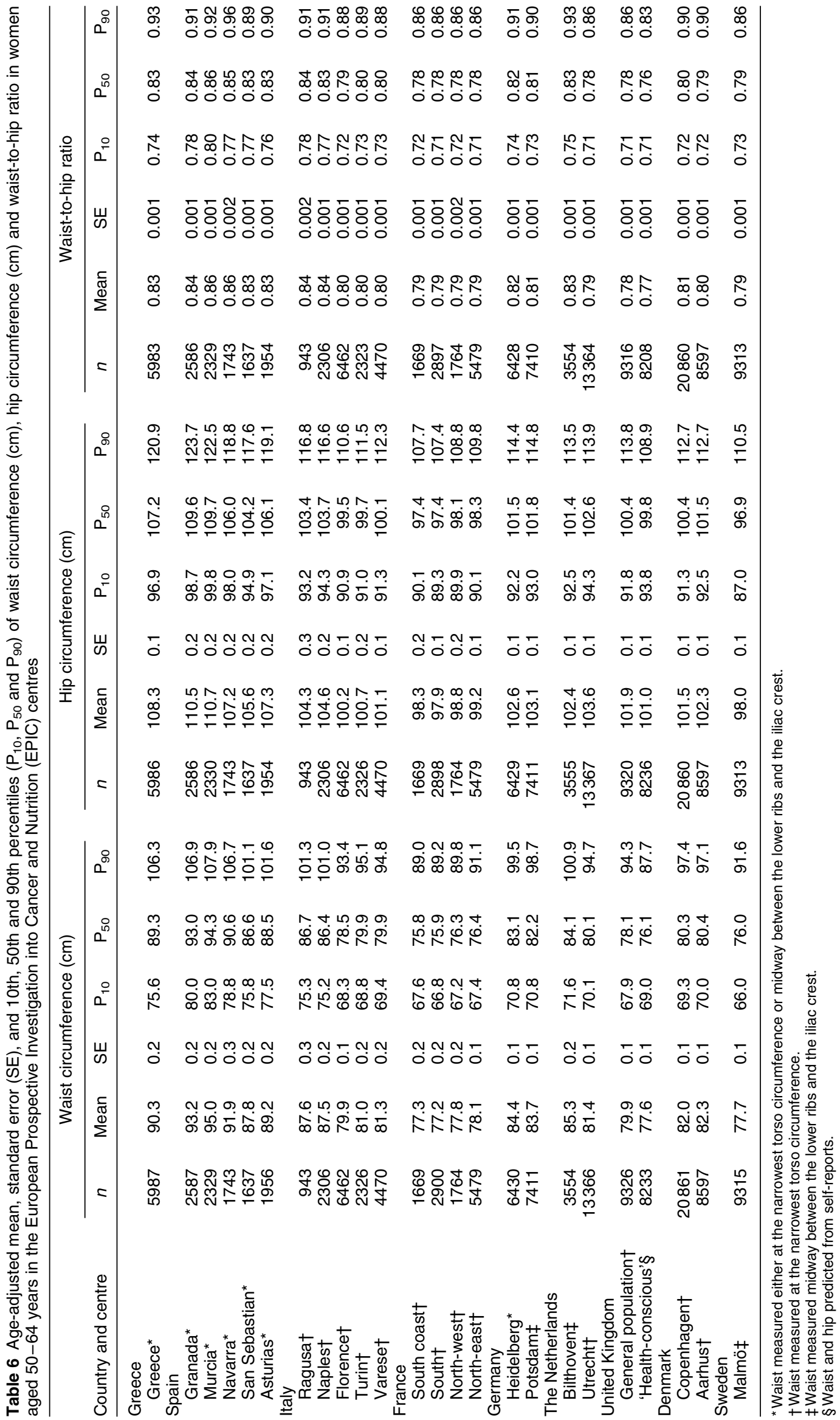


Table 7 Prevalence of large waist circumference (WC) and high waist-to-hip ratio (WHR) in men and women aged 50-64 years from different European Prospective Investigation into Cancer and Nutrition (EPIC) centres (adjusted for age)

\begin{tabular}{|c|c|c|c|c|c|c|}
\hline \multirow[b]{2}{*}{ Country and centre } & \multicolumn{3}{|c|}{ Men } & \multicolumn{3}{|c|}{ Women } \\
\hline & $n$ & $\begin{array}{c}\text { Large WC } \\
(\geq 102 \mathrm{~cm})(\%)\end{array}$ & $\begin{array}{c}\text { High WHR } \\
(\geq 0.95)(\%)\end{array}$ & $n$ & $\begin{array}{c}\text { Large WC } \\
(\geq 88 \mathrm{~cm})(\%)\end{array}$ & $\begin{array}{l}\text { High WHR } \\
(\geq 0.80)(\%)\end{array}$ \\
\hline \multicolumn{7}{|l|}{ Greece } \\
\hline Greece* & 3668 & 38.8 & 63.8 & 5987 & 54.5 & 65.8 \\
\hline \multicolumn{7}{|l|}{ Spain } \\
\hline Granada* & 891 & 49.7 & 62.7 & 2587 & 68.3 & 80.9 \\
\hline Murcia* & 1287 & 52.3 & 63.3 & 2329 & 76.3 & 88.2 \\
\hline Navarra* & 1915 & 51.6 & 64.1 & 1743 & 60.6 & 78.5 \\
\hline San Sebastian* & 2145 & 34.8 & 46.7 & 1637 & 44.0 & 73.2 \\
\hline Asturias* & 1357 & 34.1 & 43.6 & 1956 & 52.7 & 72.6 \\
\hline \multicolumn{7}{|l|}{ Italy } \\
\hline Ragusa† & 1057 & 29.2 & 69.8 & 943 & 43.9 & 78.3 \\
\hline Naples†‡ & - & - & - & 2306 & 44.7 & 72.6 \\
\hline Florence† & 1449 & 14.1 & 37.4 & 6462 & 19.2 & 43.3 \\
\hline Turint & 2747 & 18.9 & 39.8 & 2326 & 21.7 & 49.9 \\
\hline Varese† & 1588 & 14.6 & 38.7 & 4470 & 22.9 & 51.0 \\
\hline \multicolumn{7}{|l|}{ France } \\
\hline South coast†‡ & - & - & - & 1669 & 11.3 & 34.2 \\
\hline South†‡ & - & - & - & 2900 & 11.9 & 36.2 \\
\hline North-west†‡ & - & - & - & 1764 & 12.9 & 35.4 \\
\hline North-east†‡ & - & - & - & 5479 & 14.7 & 34.7 \\
\hline \multicolumn{7}{|l|}{ Germany } \\
\hline Heidelberg* & 7218 & 29.3 & 50.4 & 6430 & 33.5 & 60.1 \\
\hline Potsdam§ & 6123 & 25.0 & 53.8 & 7411 & 30.9 & 53.9 \\
\hline \multicolumn{7}{|l|}{ The Netherlands } \\
\hline Bilthoven§ & 3226 & 23.9 & 50.1 & 3554 & 36.8 & 66.1 \\
\hline Utrecht†‡ & - & - & - & 13366 & 22.5 & 37.2 \\
\hline \multicolumn{7}{|l|}{ United Kingdom } \\
\hline General populationt & 6470 & 16.2 & 32.6 & 9326 & 19.8 & 35.4 \\
\hline 'Health-conscious' & 2434 & 8.9 & 17.3 & 8233 & 9.4 & 21.8 \\
\hline \multicolumn{7}{|l|}{ Denmark } \\
\hline Copenhagent & 18526 & 23.5 & 53.4 & 20861 & 25.7 & 50.0 \\
\hline Aarhus $\dagger$ & 8323 & 25.2 & 49.1 & 8597 & 25.8 & 46.9 \\
\hline \multicolumn{7}{|l|}{ Sweden } \\
\hline Malmö§ & 7295 & 18.4 & 44.5 & 9315 & 15.0 & 40.3 \\
\hline
\end{tabular}

* Waist measured either at the narrowest torso circumference or midway between the lower ribs and the iliac crest.

† Waist measured at the narrowest torso circumference.

$\ddagger$ Only women.

$\S$ Waist measured midway between the lower ribs and the iliac crest.

ๆ Waist and hip predicted from self-reports.

attending breast cancer screening, indicating that the latter are selected in the direction of a healthier lifestyle. In the UK, mean weight and BMI, as well as the prevalence of overweight and obesity, were considerably lower in subjects from the 'health-conscious' group than in the general population cohort.

Overall, the mean BMI of most EPIC centres exceeded $25 \mathrm{~kg} \mathrm{~m}^{-2}$. More than $50 \%$ of all EPIC participants were overweight or obese. The prevalence of obesity was lowest in the French centres and the 'health-conscious' group (UK) and highest in the most southern EPIC centres (Granada, Murcia and Navarra, Spain; Naples and Ragusa, Italy; Greece).

Despite co-ordinated planning, complete standardisation of anthropometric measurement procedures was not achieved in EPIC, partly due to pre-existing protocols in cohorts joining EPIC after study inception and partly due to logistic constraints. Measurements of height were considered comparable, as were those of weight, after adjustment for clothing. Furthermore, waist and hip circumferences were corrected for clothing. Other methodological differences for measurement of WC, with consequences for WHR, are still prevailing due to lack of adequate standardisation of measurement techniques. In a previous report on 437 European women aged 38 years $^{34}$, measurements of $\mathrm{WC}$ at the narrowest circumference were on average $2.7 \mathrm{~cm}$ lower than measurements of WC midway between the lower ribs and the iliac crest. No evidence for systemic differences between these methods in middle-aged subjects has been found in the literature, but this methodological inconsistency may affect comparison of WC and WHR data from the different EPIC populations described here. Such systematic error may affect the ranking of a centre; however, for the present analysis, it is likely that interindividual variation is by far a more important source of variation than the potentially existing systematic error.

Another methodological issue may be the use of selfreported values as estimators of anthropometric measures in the 'health-conscious' group (UK). The use of 

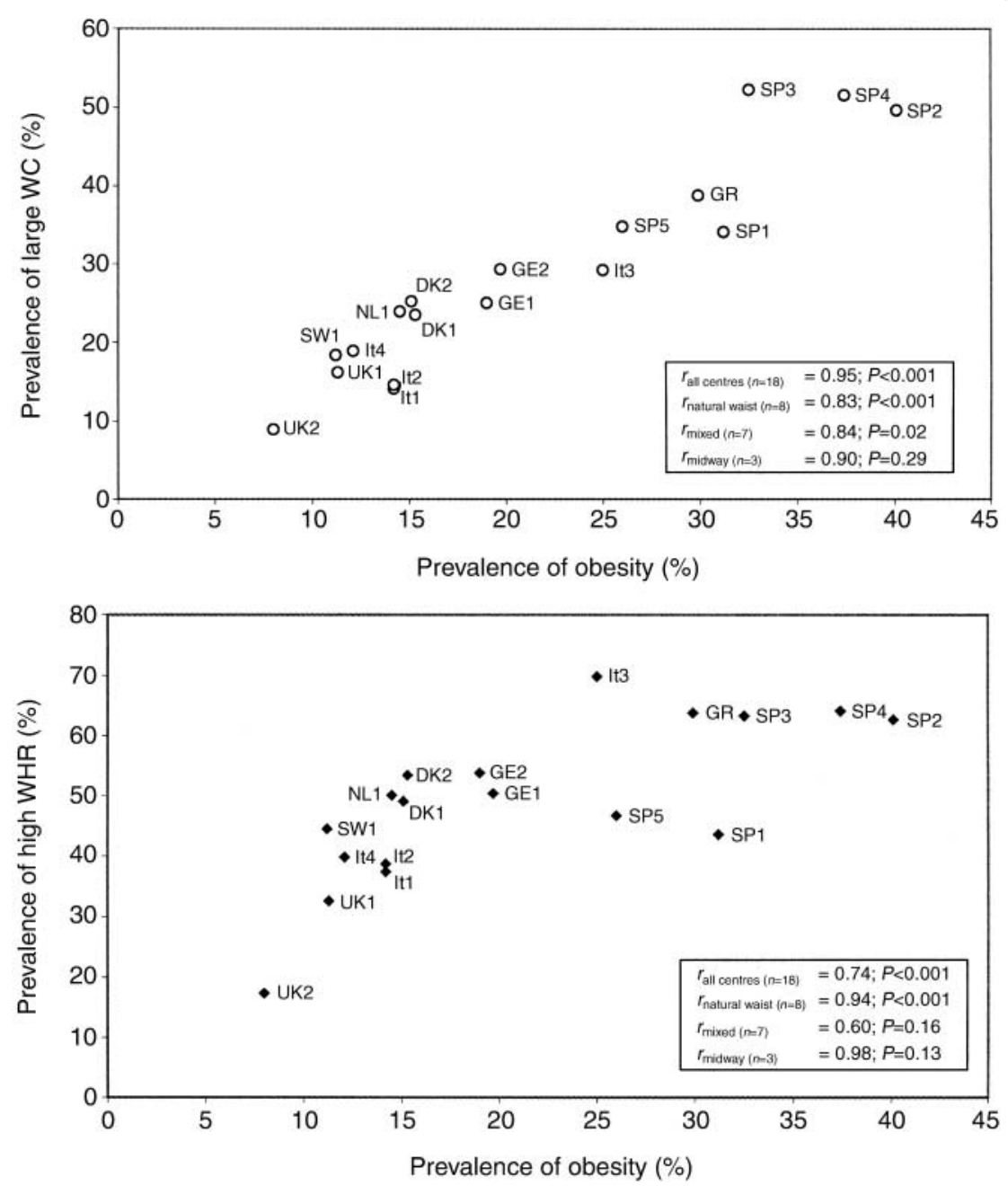

Fig. 1 The prevalence of large waist circumference (WC; top panel) and high waist-to-hip ratio (WHR; lower panel) in relation to the prevalence of general obesity in men. Abbreviations: It1 - Florence, Italy; It2 - Varese, Italy; It3 - Ragusa, Italy; It4 - Turin, Italy; SP1 - Asturias, Spain; SP2 - Granada, Spain; SP3, Murcia, Spain; SP4 - Navarra, Spain; SP5 - San Sebastian, Spain; UK1 - general population, UK; UK2 - 'health-conscious' group, UK; NL1 - Bilthoven, The Netherlands; GR - Greece; GE1 - Heidelberg, Germany; GE2 - Potsdam, Germany; SW1 - Malmö, Sweden, DK1 - Aarhus, Denmark; DK2 - Copenhagen, Denmark

prediction equations significantly reduced the proportion of misclassification in BMI groups from $22 \%$ to $15 \%$ in men and from $18 \%$ to $14 \%$ in women, for self-reported vs. predicted values, and thereby enhanced the accuracy of self-reported values (data not shown).

Prediction equations, such as those used to assess anthropometric measures from self-reports in the "healthconscious' group (UK), could not be determined for the French participants. In the latter case, the time interval between measurements and self-reports was too long for the determination of reliable predictions in the majority of participants with both examination and self-reports. Tables 3 and 4 present data from both the anthropometric examination and the self-reports for all French women. Underestimation of weight and overestimation of height seem to be present in the self-reported values. However, owing to the time interval between measurements and self-reports, no definite conclusions can be drawn regarding misclassification by self-reports.
In most EPIC centres, WC was measured at the narrowest torso circumference. Comparing results from these centres, a considerable variation of $\mathrm{WC}, \mathrm{HC}$ and WHR was observed. WC and WHR of the Italian centres of Ragusa and Naples and of the Spanish and Greek centres (most participants were measured at the narrowest area) were notably high. Assuming that measurements at the narrowest circumference are systematically lower than measurements at midway between the lower ribs and the iliac crest, this indicates even higher WC in these centres relative to other centres. The high values for WC in the southern centres were associated with high BMI in these centres.

Although both WC and WHR are used as measures of abdominal fatness, the variation in the proportion of subjects with a high WHR was not identical across centres to that in the proportion of subjects with a large WC. The greatest discrepancy between both measures was observed in men and women from the Ragusa (Italy) 

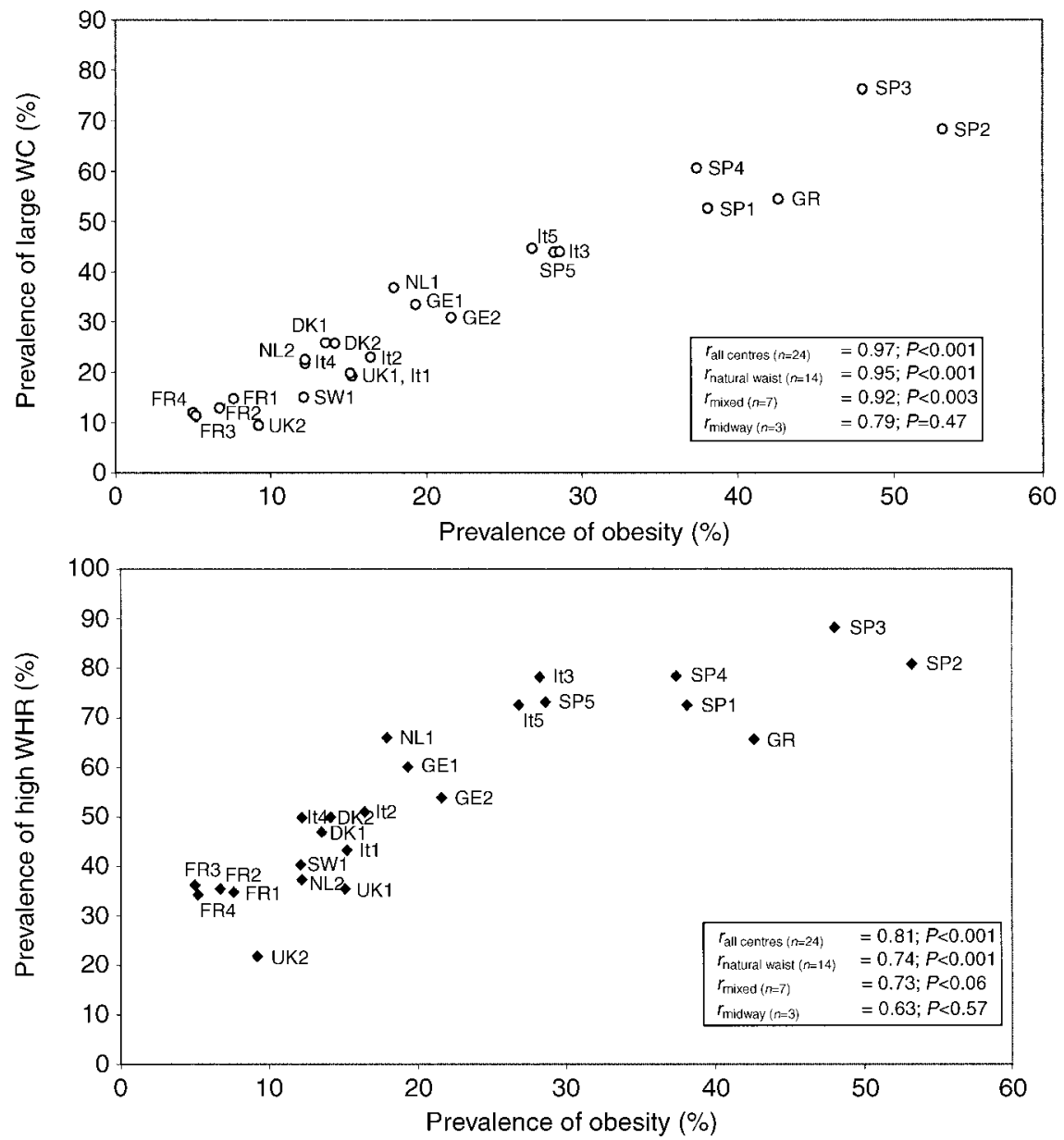

Fig. 2 The prevalence of large waist circumference (WC; top panel) and high waist-to-hip ratio (WHR; lower panel) in relation to the prevalence of general obesity in women. Abbreviations: FR1 - North-east of France; FR2 - North-west of France; FR3 - South of France; FR4 - South coast of France; It1 - Florence, Italy; It2 - Varese, Italy; It3 - Ragusa, Italy; It4 - Turin, Italy; It5 - Naples, Italy; SP1 - Asturias, Spain; SP2 - Granada, Spain; SP3, Murcia, Spain; SP4 - Navarra, Spain; SP5 - San Sebastian, Spain; UK1 - general population, UK; UK2 - 'health-conscious' group, UK; NL1 - Bilthoven, The Netherlands; NL2 - Utrecht, The Netherlands; GR - Greece; GE1 - Heidelberg, Germany; GE2 - Potsdam, Germany; SW1 - Malmö, Sweden, DK1 - Aarhus, Denmark; DK2 - Copenhagen, Denmark

centre: about $30 \%$ of the subjects had a large WC, while over $70 \%$ had a high WHR. The difference between these two measures of central adiposity is in part due to the chosen cut-off points used for WHR and WC. A relative consensus for classification based on WC was found in the literature. However, this classification remains somewhat arbitrary. There is less of a consensus on cut-off points for $\mathrm{WHR}^{35}$. We examined the different cut-off points for WHR reviewed by Molarius and Seidell ${ }^{35}$. As expected, the proportion of subjects with a high WHR was considerably smaller when a higher cut-off point was used. In addition, different cut-off points for WHR resulted in different rankings of the centres regarding the prevalence of high WHR (data not shown). Besides the issue of appropriate cut-off points, our data also indicate that WHR and WC seem to measure different aspects of obesity. The correlation coefficients for the association between WC and WHR were lower $(0.58-0.81)$ than the correlation coefficients for the association between WC and BMI (0.71-0.89). In addition, BMI is more clearly associated with WC (correlation coefficients $>0.70$ ) than with WHR (correlation coefficients $<0.62$ ). Currently, there is no consensus on the most appropriate measure for abdominal fatness ${ }^{35}$ and both WC and WHR should be used as indicators of fat distribution.

Our analyses were restricted to participants aged 50-64 years, because this age group was represented in all EPIC centres. The examination of anthropometric characteristics in younger age groups is also of interest, particularly in women, since there is a difference in the effect of weight on breast cancer in premenopausal and postmenopausal women $^{11,12}$. A detailed description of anthropometric characteristics was not intended here, but additional analyses using data from the centres including younger age groups (France, 40-50 years; Italy, Spain, general population of the UK, Germany, 35-50 years; Umeå (Sweden), 29-50 years; Malmö (Sweden), 45-50 years; 'health-conscious' group (UK), Greece, Bilthoven (The Netherlands), 20-50 years) showed a lower prevalence of general and central obesity in participants younger than 50 
years, compared with the age group 50-64 years. The geographical distribution in the prevalence of both general and central obesity across centres was similar in both age groups, with relatively high values in centres from Spain, Greece and the Italian centres of Naples and Ragusa, lower values in the northern centres and the lowest values in centres from France and the 'healthconscious' group (UK) (data not shown).

One of the most striking results of this study was the finding of high values for BMI, WC and WHR in the populations from southern Europe, especially in view of the results of another large study involving various European populations: the World Health Organization's MONICA study (MONItoring trends and determinants in CArdiovascular disease), covering the age range 35-64 years. This study did not observe an excess of adiposity in the centres of the Mediterranean area ${ }^{36}$. The Spanish and Italian regions included in the MONICA study were located in the north, while the EPIC study centres with extremely high values were in the south of Italy and Spain. The north-south gradient in the prevalence of obesity in Spain $^{31,33}$ and Italy ${ }^{32}$ may explain part of the discrepancy between results of the MONICA study and EPIC. There is also, however, strong evidence for a secular increase of general and central obesity ${ }^{1,31,37,38}$, since EPIC's baseline data were collected about 5 years later than the latest MONICA survey.

The finding of high values for anthropometric characteristics in the southern European populations is not (yet) reflected in disease risk expected from these high values. In Mediterranean countries, the absolute risk of obesity-related diseases such as coronary heart disease is among the lowest in Europe ${ }^{39}$. Further followup of the cohorts will reveal how obesity-related diseases develop in these countries. It will also be of interest to examine how obesity interacts with other factors such as the Mediterranean diet or low prevalence of smoking, especially in the older Greek and Spanish women. Obesity results from a number of different behaviours, including dietary patterns and physical inactivity. The effect of different lifestyles on body size may differ in magnitude in different populations. The predictive value of different measures of obesity for chronic diseases such as coronary heart disease is not consistent and this may reflect the different aetiological factors involved in obesity. Thus, a comparative study of obesity and its correlates and their predictive value for various chronic diseases in the EPIC study populations is of interest in the future.

In summary, a wide variation in anthropometric characteristics has been observed at baseline across different centres within the EPIC study, providing a strong starting point for an in-depth examination of the effects of body size and shape on the risk of chronic diseases, especially cancer, in different European study populations.

\section{Acknowledgements}

The work described in this paper was carried out with financial support of the 'Europe Against Cancer Programme' of the European Commission (SANCO); Ligue contre le Cancer (France); Société $3 \mathrm{M}$ (France); Mutuelle Générale de l'Education Nationale; Institut National de la Santé et de la Recherche Médicale (INSERM); Institute Gustave Roussy; German Cancer Aid; German Cancer Research Centre; German Federal Ministry of Education and Research; Danish Cancer Society; Health Research Fund (FIS) of the Spanish Ministry of Health; the Spanish Regional Governments of Andalucia, Asturias, Basque Country, Murcia and Navarra; Cancer Research UK; Medical Research Council, UK; Stroke Association, UK; British Heart Foundation; Department of Health, UK; Food Standards Agency, UK; Wellcome Trust, UK; Greek Ministry of Health; Greek Ministry of Education; Italian Association for Research on Cancer; Italian National Research Council; Dutch Ministry of Public Health, Welfare and Sports; Dutch Prevention Funds; LK Research Funds; Dutch ZON (Zorg Onderzoek Nederland); World Cancer Research Fund; Swedish Cancer Society; Swedish Scientific Council; Regional Government of Skane, Sweden; Norwegian Cancer Society; Norwegian Research Council. Partial support for the publication of this supplement was provided by the Centre de Recherche et d'Information Nutritionnelles (CERIN).

In addition, we wish to thank all study participants for their co-operation and all interviewers who participated in the fieldwork studies in each EPIC centre.

\section{References}

1 World Health Organization (WHO). Obesity: Preventing and Managing the Global Epidemic. Report of a WHO Consultation. WHO Technical Report Series No. 894. Geneva: WHO, 2000.

2 National Institutes of Health. Clinical guidelines on the identification, evaluation, and treatment of overweight and obesity in adults - the evidence report. Obes. Res. 1998; 6(Suppl. 2): 51S-209S.

3 Seidell JC, Kahn HS, Williamson DF, Lissner L, Valdez R. Report from a Centers for Disease Control and Prevention Workshop on use of adult anthropometry for public health and primary care health care. Am. J. Clin. Nutr. 2001; 73: 123-6.

4 Seidell JC. Obesity, insulin resistance and diabetes - a worldwide epidemic. Br. J. Nutr. 2000; 83(Suppl. 1): S5-8.

5 Rodriguez C, Patel AV, Calle EE, Jacobs EJ, Chao A, Thun MJ. Body mass index, height and prostate cancer mortality in two large cohorts of adult men in the United States. Cancer Epidemiol. Biomark. Prev. 2001; 10: 345-53.

6 Hsing AW, Deng H, Sesterhenn IA, Mostofi FK, Stanczyk FZ, Benichou $\mathrm{J}$, et al. Body size and prostate cancer: a population-based case-control study in China. Cancer Epidemiol. Biomark. Prev. 2000; 9: 1335-41.

7 Ford ES. Body mass index and colon cancer in a national sample of adult US men and women. Am. J. Epidemiol. 1999; 150: $390-8$.

8 Caan BJ, Coates AO, Slattery ML, Potter JD, Quesenberry CP 
Jr, Edwards SM. Body size and the risk of colon cancer in a large case-control study. Int. J. Obes. Relat. Metab. Disord. 1998; 22: 178-84.

9 Goodman MT, Hankin JH, Wilkens LR, Lyu LC, McDuffie K, Liu LQ, et al. Diet, body size, physical activity, and the risk of endometrial cancer. Cancer Res. 1997; 57: 5077-85.

10 Stoll BA. Adiposity as a risk determinant for postmenopausal breast cancer. Int. J. Obes. Relat. Metab. Disord. 2000; 24: 527-33.

11 Sonnenschein E, Toniolo P, Terry MB, Bruning PF, Kato I, Koenig KL, et al. Body fat distribution and obesity in pre- and postmenopausal breast cancer. Int. J. Epidemiol. 1999; 28: 1026-33.

12 Van den Brandt P, Spiegelman D, Yuan SS, Adami HO, Beesom L, Folsom AR, et al. Pooled analysis of prospective cohort studies on height, weight and breast cancer risk. Am. J. Epidemiol. 2000; 152: 514-27.

13 Murphy TK, Calle EE, Rodriguez C, Kahn HS, Thun MJ. Body mass index and colon cancer mortality in a large prospective study. Am. J. Epidemiol. 2000; 152: 847-54.

14 Huang Z, Willet WC, Colditz GA, Hunter DJ, Manson JE, Rosner B, et al. Waist circumference, waist:hip ratio, and risk of breast cancer in the Nurses' Health Study. Am. J. Epidemiol. 1999; 150: 1316-24.

15 Vainio H, Bianchini F, Cheney J, eds. IARC Handbook of Cancer Prevention. Vol. 6. Weight Control and Physical Activity. Lyon: IARC Press, 2002.

16 Chow WH, Gridley G, Fraumeni JF, Jarvholm B. Obesity, hypertension and the risk of kidney cancer in men. $N$. Engl. J. Med. 2000; 343(18): 1305-11.

17 Chow WH, Blot WJL, Vaughan TL, Risch HA, Gammon MD, Stanford JL, et al. Body mass index and risk of adenocarcinomas of the esophagus and gastric cardia. J. Natl. Cancer Inst. 1998; 90: 150-5.

18 Rimm EB, Stampfer MJ, Giovannucci E, Ascherio A, Spiegelman D, Colditz GA, et al. Body size and fat distribution as predictors of coronary heart disease among middle-aged and older US men. Am. J. Epidemiol. 1995; 141: $1117-27$.

19 Visscher TLS, Seidell JC, Menotti A, Blackburn H, Nissinen A, Feskens EJM, et al. Underweight and overweight in relation to mortality among men aged $40-59$ and $50-59$ years. Am. J. Epidemiol. 2000; 151: 660-6.

20 Lahmann PH, Lissner L, Gullberg B, Berglund G. A prospective study of adiposity and all-cause mortality: The Malmö Diet and Cancer Study. Obes. Res. 2002; 10: 361-9.

21 Larsson B, Svärdsudd K, Welin L, Wilhelmsen L, Björntorp P, Tibblin G. Abdominal adipose tissue distribution, obesity, and risk of cardiovascular disease and death: 13-year followup of participants in the study of men born in 1913. Br. Med. J. 1984; 288: 1401-4.

22 Hartz AJ, Rupley DC, Rimm AA. The association of girth measurements with disease in 32,856 women. Am. J. Epidemiol. 1984; 119: 71-80.

23 Gupta R, Majumdar S. Correlation of waist-hip ratio with coronary heart disease and risk factor prevalence in a rural male population. Indian Heart J. 1994; 46: 145-8.

24 Riboli E, Kaaks R. The EPIC Project: rationale and study design. Int. J. Epidemiol. 1997; 26(Suppl. 1): S6-14.

25 Riboli E, Hunt KJ, Slimani N, Ferrari P, Norat T, Fahey M, et al. European Prospective Investigation into Cancer and Nutrition (EPIC) study: study populations and data collection. Public Health Nutr. 2002; 5(6B): 1113-24.

26 Lohman TG, Roche AF, Martorell R. Anthropometric Standardization Reference Manual. Champaign, IL: Human Kinetics Books, 1991.

27 De Groot CPGM, Sette S, Zajkás G, Carbajal A, Amorim Cruz JA. Nutritional status: anthropometry. Eur.J. Clin. Nutr. 1991; 45(Suppl. 3): 43-52.

28 Lean MEJ, Han TS, Morrison CE. Waist circumference as a measure for indicating need for weight management. $B r$. Med.J. 1995; 311: 158-61.

29 Slimani N, Kaaks R, Ferrari P, Casagrande C, Clavel-Chapelon F, Lotze G, et al. European Prospective Investigation into Cancer and Nutrition (EPIC) calibration study: rationale, design and population characteristics. Public Health Nutr. 2002; 5(6B): 1125-45.

30 Molarius A, Seidell JC, Sans S, Tuomilehto J, Kuulasmaa K. Waist and hip circumferences, and waist-hip ratio in 19 populations of the WHO MONICA Project. Int.J. Obes. Relat. Metab. Disord. 1999; 23: 116-25.

31 Gutiérrez-Fisac JL, Banegas Banegas JR, Rodriguez Artalejo $\mathrm{F}$, Regidor E. Increasing prevalence of overweight and obesity among Spanish adults, 1987-1997. Int.J. Obes. Relat. Metab. Disord. 2000; 24: 1677-82.

32 Pagano R, La Vecchia C. Overweight and obesity in Italy, 1990-91. Int. J. Obes. Relat. Metab. Disord. 1994; 18: 665-9.

33 Aranceta J, Perez-Rodrigo C, Serra-Majem L, Ribas L, Quiles Izquierdo J, Vioque J, et al. Spanish Collaborative Group for the Study of Obesity in Spain. Influence of sociodemographic factors in the prevalence of obesity in Spain. The SEEDO'97 study of obesity. Eur. J. Clin. Nutr. 2001; 55: $430-5$.

34 Seidell JC, Cigolini M, Charzewska J, Ellsinger B-M, Di Biase G. Fat distribution in European women: a comparison of anthropometric measurements in relation to cardiovascular risk factors. Int. J. Epidemiol. 1990; 19: 303-8.

35 Molarius A, Seidell JC. Selection of anthropometric indicators for classification of abdominal fatness - a critical review. Int . J. Obes. 1998; 22: 719-22.

36 Molarius A, Seidell JC, Sans S, Tuomilehto J, Kuulasmaa K. Educational level, relative body weight and changes in their association over 10 years: an international perspective from the WHO MONICA project. Am. J. Public Health 2000; 90: $1260-8$.

37 Lahti-Koski M, Pietinen P, Mämmistö S, Vartiainen E. Trends in waist-to-hip ratio and its determinants in adults in Finland from 1987-1997. Am. J. Clin. Nutr. 2000; 72: 1436-1444.

38 Lissner L, Björkelund C, Heitmann BL, Lapidus L, Björntorp $\mathrm{P}$, Bengtsson C. Secular increases in waist-hip ratio among Swedish women. Int. J. Obes. Relat. Metab. Disord. 1998; 22: $1116-20$.

39 World Health Organization (WHO). WHO Health Report 2000. Geneva: WHO, 2000.

\section{Appendix - Prediction equations of weight, height, and waist and hip circumferences from self-reported values and age in men and women from the UK representing the 'health-conscious' group}

Men:

$$
\begin{aligned}
& \text { Weight }=0.561+(1.012 \times \text { sr_weight })+(0.006 \times \text { age }) \\
& \text { Height }=15.032+(0.923 \times \text { sr_height })-(0.052 \times \text { age })
\end{aligned}
$$$$
\text { Waist }=7.791+(0.972 \times \text { sr_waist })-(0.035 \times \text { age })
$$$$
\text { Hip }=42.812+(0.637 \times \text { sr_hip })-(0.075 \times \text { age })
$$ 
Women:

Weight $=0.444+(1.010 \times$ sr_weight $)+(0.006 \times$ age $)$

Height $=27.096+(0.853 \times$ sr_height $)-(0.069 \times$ age $)$

Waist $=9.022+(0.847 \times$ sr_waist $)+(0.091 \times$ age $)$

Hip $=20.040+(0.818 \times$ sr_hip $)-(0.011 \times$ age $)$
In the above equations, sr_weight is self-reported weight, sr_height is self-reported height, sr_waist is selfreported waist circumference and sr_hip is self-reported hip circumference. Weight is in $\mathrm{kg}$; height, waist circumference and hip circumference are in $\mathrm{cm}$; age is in years. 